\title{
References of Birth Weights for Gestational Age and Sex from a Large Cohort of Singleton Births in Cameroon
}

\author{
Jean Dupont Kemfang Ngowa, ${ }^{1}$ Irénée Domkam, ${ }^{2}$ Anny Ngassam, \\ Georges Nguefack-Tsague, ${ }^{3}$ Walter Dobgima Pisoh, ${ }^{1}$ Cyrille Noa, ${ }^{1}$ and Jean Marie Kasia ${ }^{1}$ \\ ${ }^{1}$ Department of Obstetrics and Gynecology, Faculty of Medicine and Biomedical Sciences, Yaounde General Hospital, \\ University of Yaounde I, P.O. Box 5408, Yaounde, Cameroon \\ ${ }^{2}$ Chantal Biya International Reference Centre for Research on HIV/AIDS Prevention and Management, \\ P.O. Box 3077, Yaounde, Cameroon \\ ${ }^{3}$ Department of Public Health, Faculty of Medicine and Biomedical Sciences, University of Yaounde I, \\ P.O. Box 1364, Yaounde, Cameroon \\ Correspondence should be addressed to Jean Dupont Kemfang Ngowa; jdkemfang@yahoo.fr
}

Received 19 January 2014; Accepted 4 April 2014; Published 12 May 2014

Academic Editor: Marc J. N. C. Keirse

Copyright (C) 2014 Jean Dupont Kemfang Ngowa et al. This is an open access article distributed under the Creative Commons Attribution License, which permits unrestricted use, distribution, and reproduction in any medium, provided the original work is properly cited.

\begin{abstract}
Objective. To establish the percentile charts of birth weights for gestational age and sex within the Cameroonian population. Methods. A review of medical records of infants born between January 2007 and December 2011 at the maternities of two hospitals in Cameroon, Central Africa. Multiple pregnancies, births of HIV infected women, stillbirths, and births with major fetal malformations were excluded. The smooth curves of birth weight for gestational age and sex were created using the Gamlss package under R.3.0.1 software. Results. The birth weights of 12837 live birth singleton infants born to HIV negative women between 28 and 42 weeks of gestation were analyzed to construct the birth weight curves for gestational age and sex. The smoothed percentile curves of birth weights for gestational age and sex of Cameroonian infants have demonstrated an increasing slope until 40 weeks and then a plateau. There was a varied difference of distribution in birth weights for gestational age between Cameroonian, Botswanan, American, and French infants. Conclusion. We established the reference curves of birth weights for gestational age and sex for Cameroonians. The difference in birth weight curves noted between Cameroonian, Botswanan, American, and French infants suggests the importance of establishing the regional birth weight norms.
\end{abstract}

\section{Introduction}

Birth weight is one of the important indicators used to assess the health of an infant at birth. It is often used as an outcome measure in perinatal research or as an indicator of perinatal health in clinical practice [1]. Gestational age is a good predictor of birth weight and perinatal survival. After the control of the effects of gestational age, birth weight alone has a strong association with perinatal survival [2]. Low birth weight has been defined by the World Health Organization (WHO) as birth weight of less than 2,500 grams. The infants weighing less than 2,500 grams are approximately 20 times more likely to die than those weighing more $[3,4]$.
Small for gestational age (birth weight $<10$ th percentile) or large for gestational age (birth weight $>90$ th percentile) babies may be identified using the centile charts of birth weight for gestational age and sex [2]. For most developing countries, data on birth weight is collected via annual demographic health survey records and birth weight for gestational age is generally unavailable $[3,4]$. However, it is well recognized that there is a wide variation in the birth weight for gestational age of infants depending on ethnicity and sex $[5,6]$. In a recent study, Matthews et al. [7] reported that preterm Botswana-born infants had higher average birth weights while term Botswana infants had lower birth weights compared to those born in the US. 
This finding confirms the geographical variability of birth weights.

In Cameroon, the reference curves for birth weight used in clinical practice are those established in the European or American populations [8,9]. The establishment of specific norms of birth weight for gestational age in a Cameroonian population may be an important step towards identifying infants at higher risk of early morbidity or death. The aim of this study was to establish the percentile charts of birth weights for gestational age and sex within the Cameroonian population.

\section{Methods}

This was a medical record review of infants born between January 2007 and December 2011 at the maternities of the Yaounde General Hospital (YGH) and Yaounde GynecoObstetric and Pediatric Hospital (YGOPH) situated in Cameroon, Central Africa. These hospitals are located in the urban setting of Yaounde and are among the most attended health centers in this town. Yaounde is the political capital of Cameroon; its population is cosmopolitan and representative of all the ethnic groups of this country. Because of their geographical location, the maternities of these two hospitals receive mothers from all ethnic groups of this country. In these maternities, birth records are filled by the midwives.

All live born singleton infants from 28 to 42 weeks of gestational age during the study period were recruited. The gestational age was calculated in completed weeks from the last menstrual period since the use of ultrasound in the dating of pregnancies is not a common practice in our milieu. The cases with major congenital abnormalities, stillbirths, HIV positive mothers, unknown and uncertain gestational age, and incomplete data were excluded from the study. Perinatal data was collected from the delivery registries and filled by midwives. This data included date of delivery, gestational age at birth, singleton birth, birth weight, infant sex, viability, stillbirths, infants with major congenital abnormalities observed, and HIV status of the mother.

The first step of the statistical analysis consisted in cleaning the outliers from the data. We used the method described by Foster and Kecojevié [10] who used a robust regression of birth weight on log transformation of gestational ages to identify the most extreme values. The observations with the big residuals are weighted down, which reflect that they are atypical from the rest of the observations when it comes to fitting such a model. Observations with zero weight are deemed to be extreme and so are then removed from the data as outliers before the construction of the curves. The zero weight does not refer to the body weight but corresponds to the zero influence of the individual in the model used. In the second step, we constructed the gender specific birth weights for gestational age curves. BCPE model with cubic smoothing spline model was used. The BCPE distribution was chosen within a set of distributions (BCPE, LNO, PE, BCT, and JSU) based on the generalised Akaike information criterion (GAIC). The Gamlss function "find.hyper" was used to select the appropriate hyperparameters for mu and sigma and the power parameters.

The smoothed percentile curves for the 10th, 25th, 50th, 75th, and 90th percentiles were created using the Gamlss package under R.3.0.1 software. Worm plots and residual plots were used to assess the normality of the curves for each sex [11] (Figures 1 and 2). The median birth weights of Cameroonian born infants at each gestational age were compared to those of Botswanan and American born infants and birth weights at 10th, 50th, and 90th centiles of Cameroonian infants were compared with those of French infants. The researchers obtained permission to carry out this study from the two hospitals management team represented in each hospital by the head of the medical team.

\section{Results}

A total of 14129 births were collected as initial dataset, of which 6480 were from the Yaounde General Hospital and 7649 were from the Yaounde Gyneco-Obstetric and Pediatric Hospital. An HIV status was recorded for $99 \%$ of the mothers, of which $02.16 \%$ (303) were HIV positive. We excluded the births from HIV positive mothers (303); mothers with unknown HIV status (122); births from multiple pregnancies (264); stillbirths (283); births with major congenital abnormalities (35); births at $<28$ or $>42$ weeks of gestational age (129); and births with unknown viability status, birth weight, or gestational age (156). After application of these exclusion criteria, we obtained 12837 live birth singleton infants without congenital abnormalities born to HIV negative women at 28-42 weeks of gestational age. Then, 153 outliers were also excluded leaving a final dataset analysis of 6263 for female infants and 6421 for male infants (Figure 3).

Crude birth weights for gestational ages ranging from 28 to 42 weeks for male and female infants are illustrated, respectively, in Tables 1 and 2. The number of infants at each gestational age ranged from 17 at 29 weeks to 1638 at 39 weeks for male infants and from 12 at 29 weeks to 1663 at 39 weeks for female infants. The median gestational age at delivery among all infants was 39 weeks and the median birth weight was $3206 \mathrm{~g}$. The male infants were generally heavier than the female infants for each gestational age with a median birth weight of $3260 \mathrm{~g}$ for the males compared to $3160 \mathrm{~g}$ for the females $(P<0.001)$. Low birth weight $(<2500 \mathrm{~g})$ represented $9.8 \%$ of the study population, with $8.3 \%$ for male infants and $11.3 \%$ for female infants.

The smoothed percentile curves for the birth weights of male and female Cameroonian infants are represented in Figure 4. These curves reveal an increasing slope until 40 weeks and then a plateau. Tables 3 and 4 display the estimated birth weight percentiles for gestational age for Cameroonian males and females, respectively.

Figure 5 shows the superimposed curves of median birth weight for gestational age constructed from the Cameroon dataset and Botswana and USA data [7]. These curves reveal that Cameroon born infants weighed less than Botswana and USA born infants between 29 and 36 weeks and between 30 


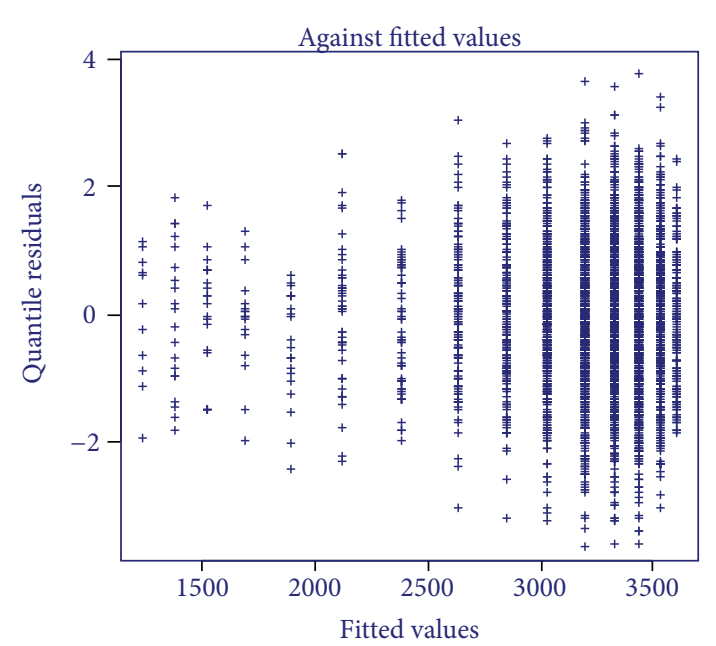

(a)

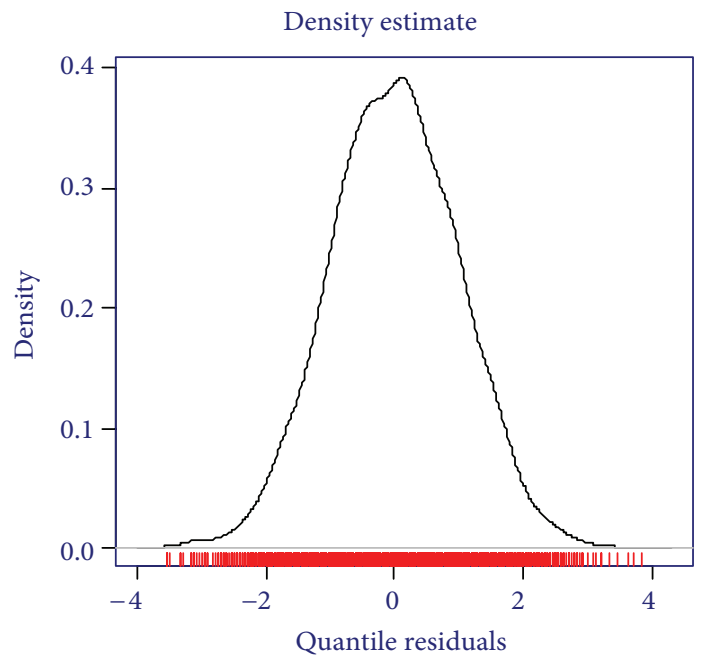

(c)

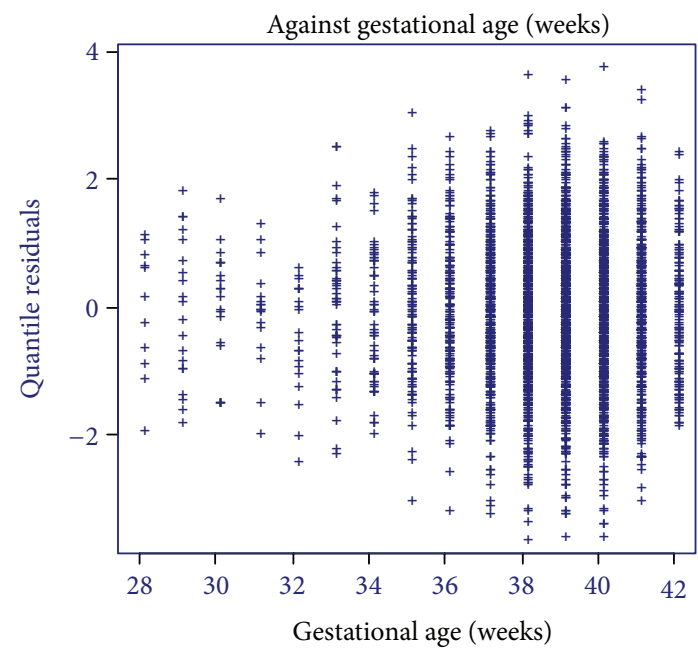

(b)

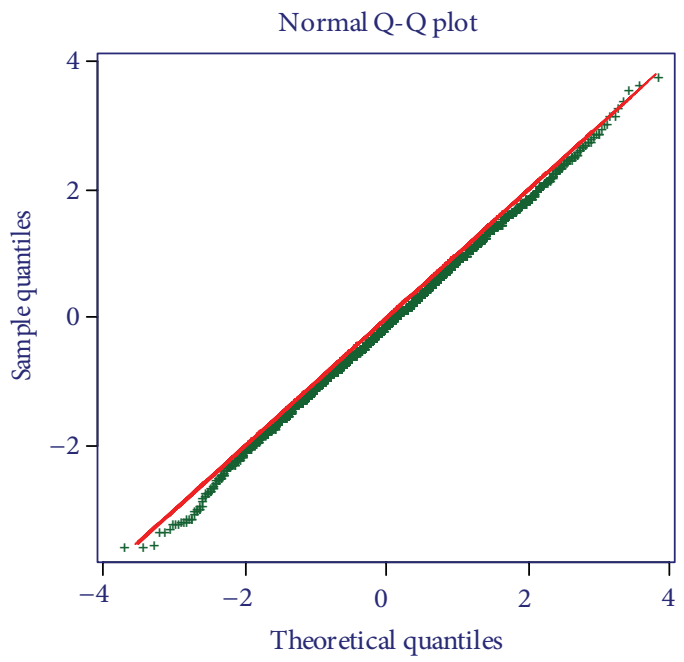

(d)

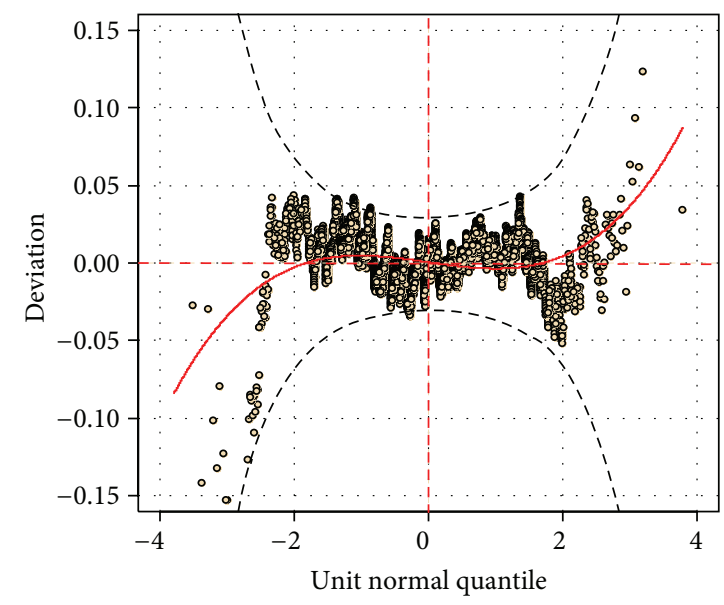

(e)

FIgURE 1: Residual and worm plots of birth weights of male Cameroonian infants. 


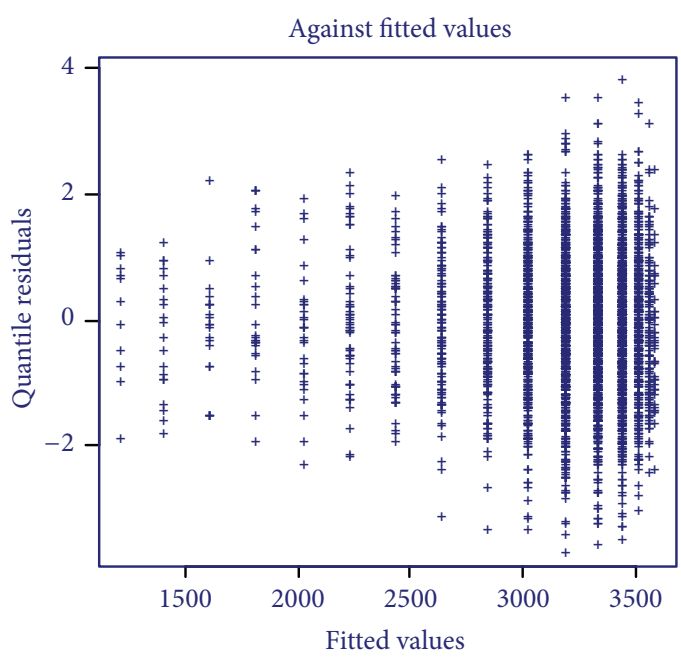

(a)

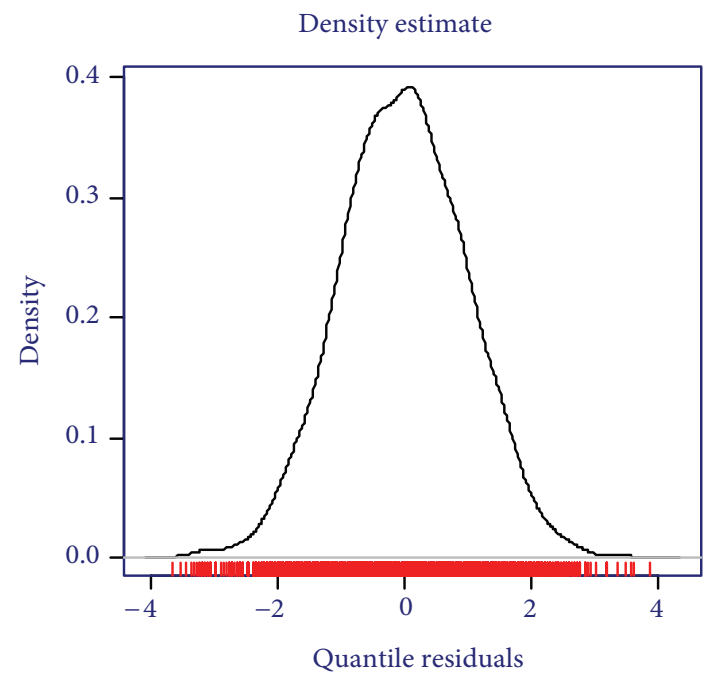

(c)

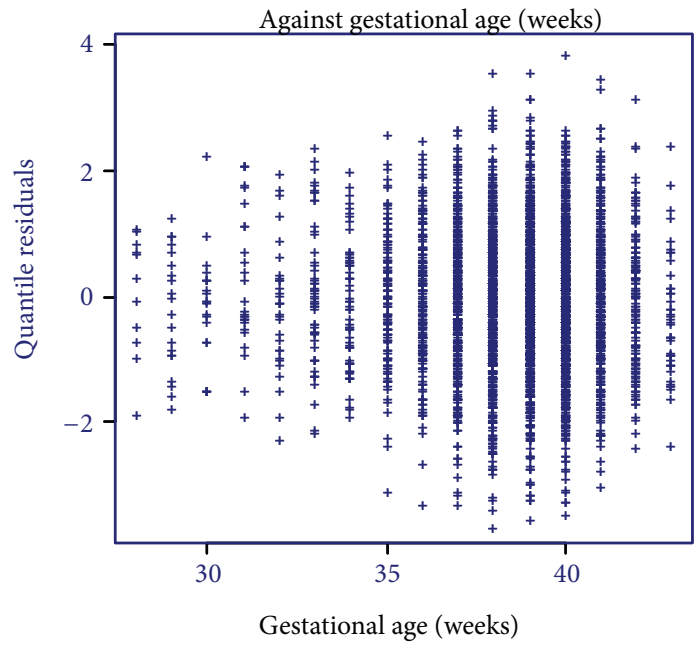

(b)

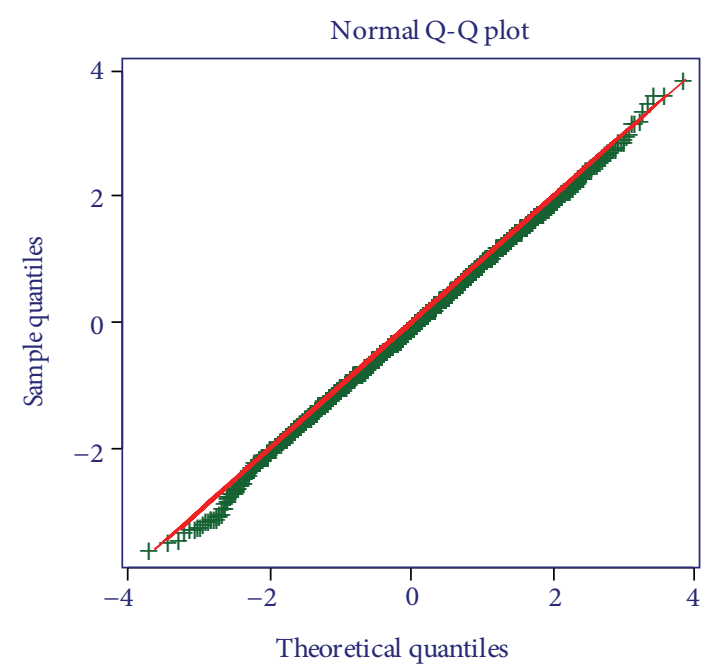

(d)

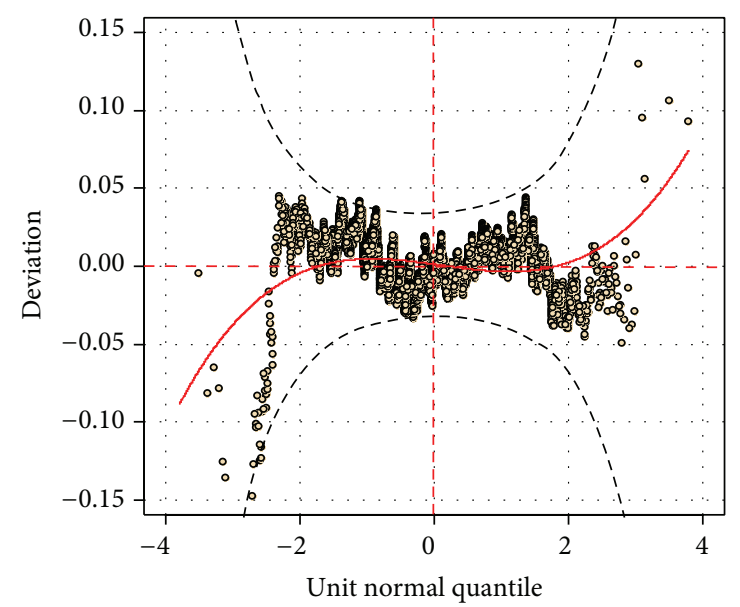

(e)

FIGURE 2: Residual and worm plots of birth weights of female Cameroonian infants. 


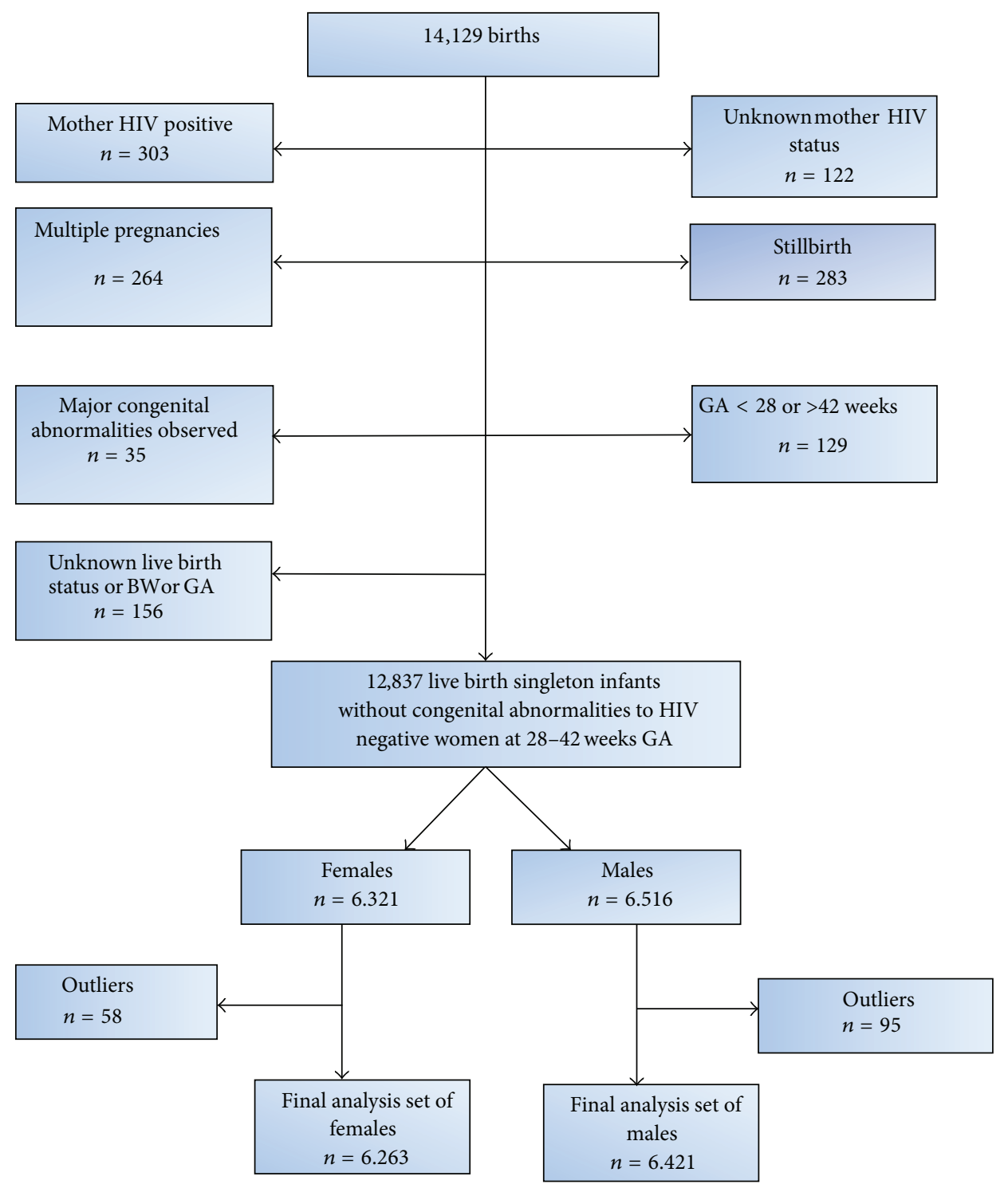

FIGURE 3: Selection of analysis dataset of births. GA: gestational age; BW: birth weight.

and 37 weeks, respectively, and they had a tendency to be heavier thereafter.

Figure 6 shows the 10th, 50th, and 90th percentile curves of Cameroon born infants compared to French born infants for males and females [9]. The curves for male infants reveal that preterm Cameroon born infants seem to be heavier than preterm French babies at 10th and 50th percentiles; however, they tend to be less heavy beyond term. Similarly, the curves for female infants reveal that Cameroon born babies tend to be heavier than the French babies at the 10th and 50th percentiles.

\section{Discussion}

This study describes percentile charts of birth weights for gestational age and sex for live singleton infants born in two hospitals in Yaounde. We believe that this hospital based data is representative of the whole Cameroonian population, since the data was collected in two of the most attended hospitals in Yaounde where the population is a mixture of people from different regions of the country. Equally, the proportion of low birth weight infants of $9.8 \%$ in this study is close to the $11 \%$ of low birth weight infants estimated in the Cameroonian population in 2003 by the UNICEF based on data of demographic and health survey [3]. This data may serve as a reference for birth weight for gestational age in this population. We believe that these curves of birth weight for gestational age will provide to obstetricians, pediatricians, and researchers a useful tool that is more suitable than American and European references for the Cameroonian population. For clinicians, it improves the classification of individual infants within the following categories: appropriate, small, or large for their gestational age. For researchers, 


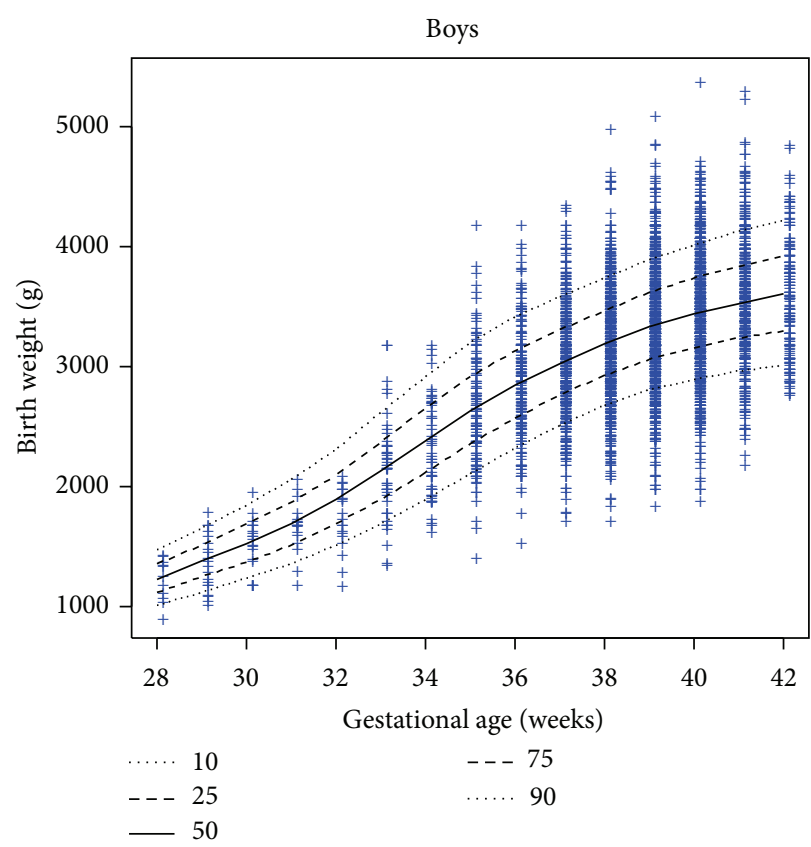

(a)

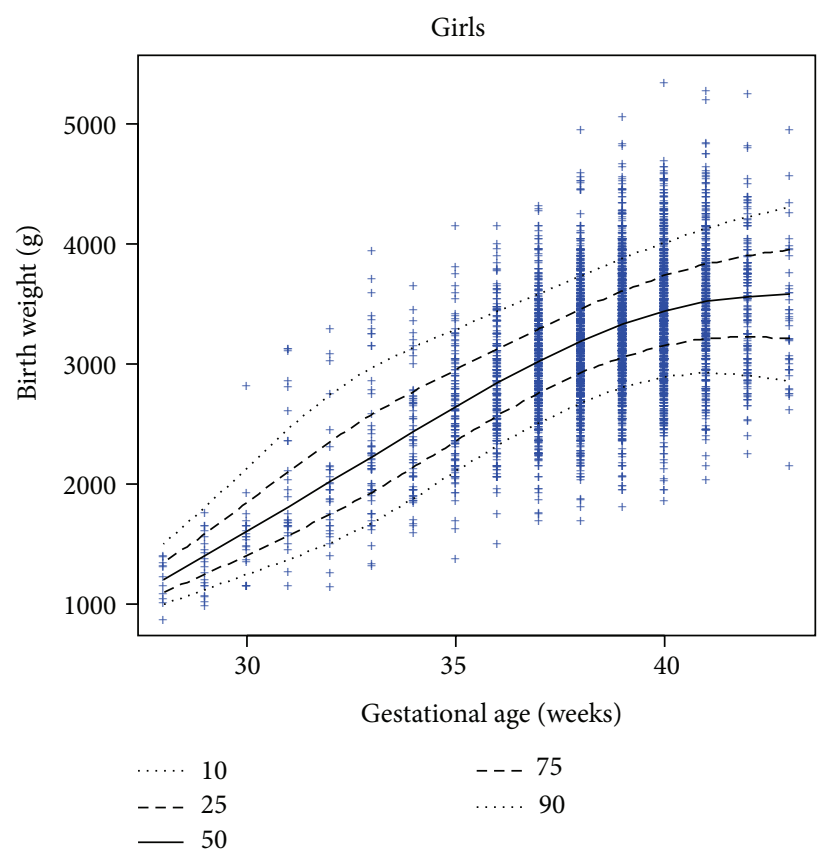

(b)

FIGURE 4: Smoothed percentile curves for the birth weights of male and female Cameroonian infants.

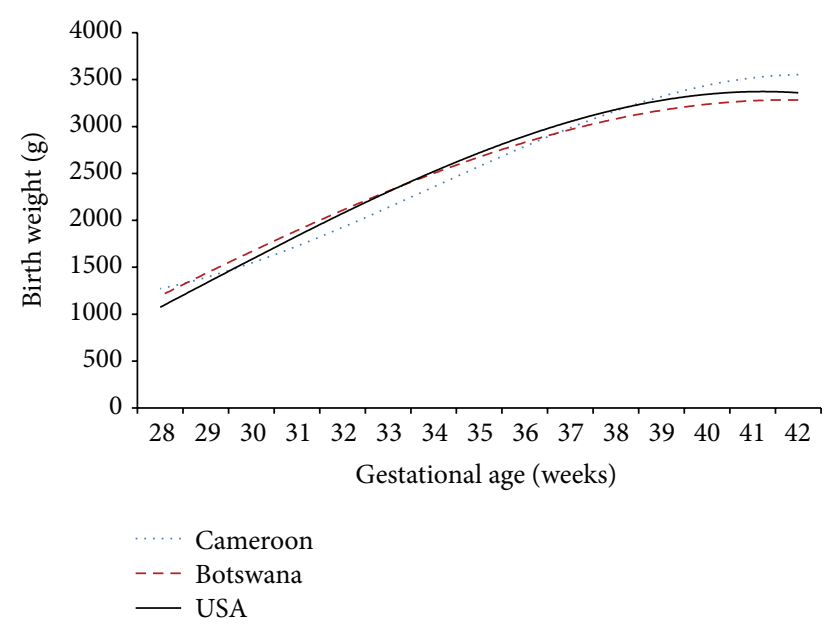

FIGURE 5: Median birth weights for gestational age of Cameroonian infants compared to those of Botswana and USA infants.

it allows a better classification of groups of infants so as to determine geographical differences, temporal trends, etiologic determinants, and short and long term prognosis.

In most developing countries, the reference of birth weight for gestational age is unavailable. In these countries, there is a lack of national birth weight registers and birth weight is collected via annual demographic health surveys [3]. As a matter of fact, currently used birth weights for gestational age references in most developing countries are those from North America or Western Europe which are not necessarily suitable for the concerned populations $[8,9,12]$.
TABLE 1: Distribution of crude birth weights for gestational age for male Cameroonian infants.

\begin{tabular}{lcccccc}
\hline $\begin{array}{l}\text { Gestational } \\
\text { age (weeks) }\end{array}$ & $n$ & \multicolumn{5}{c}{ Birth weights (grams) } \\
\hline 28 & 29 & 1109 & 181 & 1090 & 750 & 1450 \\
29 & 17 & 1383 & 237 & 1400 & 1030 & 1810 \\
30 & 22 & 1557 & 330 & 1555 & 1050 & 2620 \\
31 & 28 & 2016 & 593 & 1740 & 1200 & 3180 \\
32 & 30 & 1963 & 511 & 1965 & 1050 & 3130 \\
33 & 59 & 2381 & 642 & 2250 & 1360 & 4050 \\
34 & 67 & 2398 & 491 & 2300 & 1640 & 3700 \\
35 & 126 & 2689 & 477 & 2650 & 1420 & 4200 \\
36 & 245 & 2882 & 443 & 2860 & 1550 & 4200 \\
37 & 607 & 3048 & 421 & 3040 & 1730 & 4370 \\
38 & 1234 & 3215 & 412 & 3200 & 1740 & 5000 \\
39 & 1638 & 3347 & 429 & 3330 & 1860 & 4880 \\
40 & 1563 & 3447 & 445 & 3450 & 1900 & 4980 \\
41 & 635 & 3541 & 457 & 3540 & 2080 & 4900 \\
42 & 161 & 3535 & 519 & 3600 & 2300 & 4875 \\
\hline
\end{tabular}

SD: standard deviation.

Several studies have revealed the racial and/or ethnic and geographical variation of birth weights, with higher birth weights among European rather than African and Asian infants [5].

The difference in birth weights between Cameroonian born infants and those from Botswana and USA can be explained by the geographical variation due to environmental 

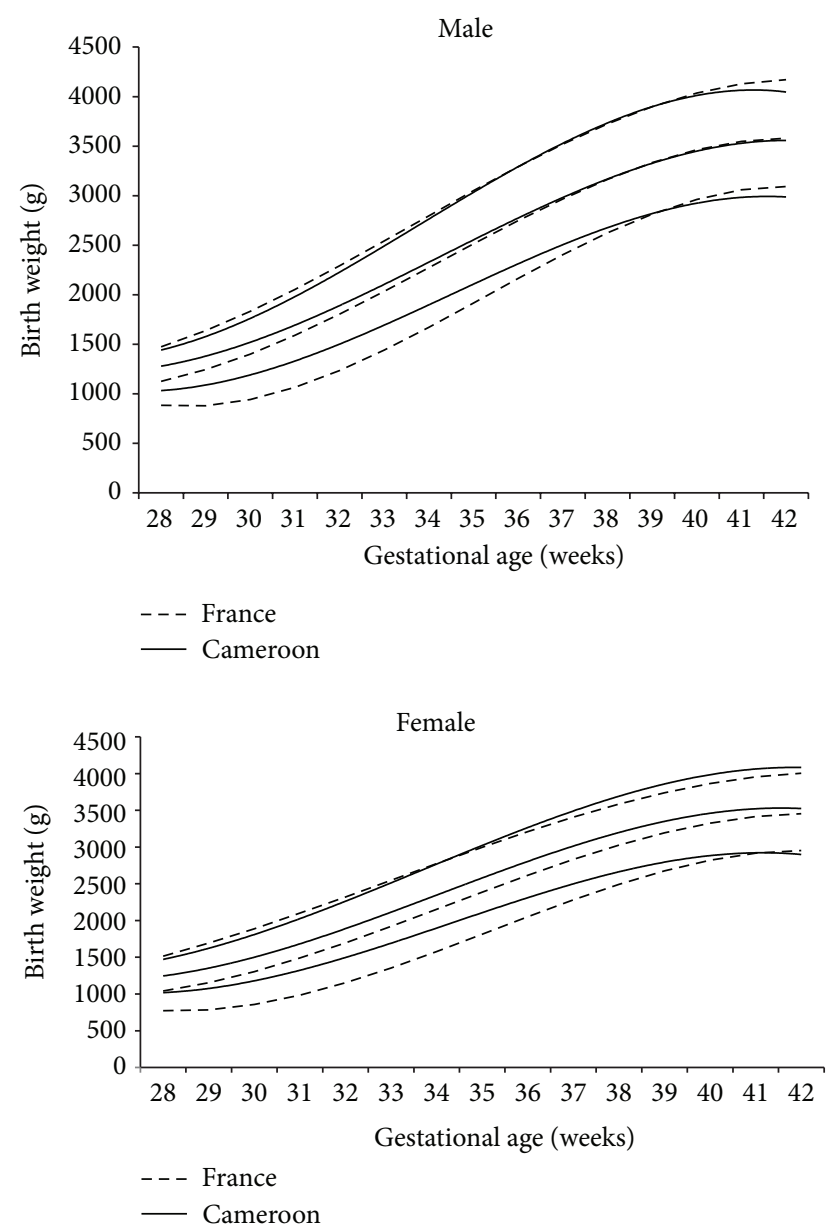

FiguRE 6: 10th, 50th, and 90th percentile curves of birth weights of male and female Cameroonian infants compared to French infants.

factors. The small sample size in preterm Cameroonian infants in both sexes and the births from multiple pregnancies included in the Botswana study could skew the data toward the lower birth weights.

We noted a difference in the curves of birth weights for gestational age of Cameroonian infants and French infants. The male Cameroonian infants born at $<35$ weeks tend to have higher birth weights than French born infants at the 10th and 50th percentiles and there after they seem to be less heavy, while the female Cameroonian infants tend to have at the 10th and 50th percentiles a higher birth weight than French female infants. The difference in birth weights for gestational age between Cameroonian and French infants can be explained by racial and geographical factors and probably the smaller sample size of preterm infants in our study. In this study, the sample size was less than 100 between 28 and 34 weeks which did not assure the best statistical strength.

One immediate impact of dating pregnancy using the last menstrual period is the misclassification of gestational age with risk of an increase or a decrease in birth weights for gestational age. This inaccuracy of dating pregnancy using the last menstrual period is due to recall bias, varied menstrual cycles, irregular cycles, and misinterpretation of bleeding at
TABLE 2: Distribution of crude birth weights for gestational age for female Cameroonian infants.

\begin{tabular}{lcccccc}
\hline $\begin{array}{l}\text { Gestational } \\
\text { age (weeks) }\end{array}$ & $n$ & \multicolumn{5}{c}{ Birth weights (grams) } \\
\hline 28 & 23 & 1053 & 207 & 1030 & 700 & 1500 \\
29 & 12 & 1342 & 339 & 1275 & 900 & 1900 \\
30 & 18 & 1581 & 435 & 1470 & 1000 & 2650 \\
31 & 25 & 1940 & 587 & 1700 & 1200 & 3050 \\
32 & 35 & 1957 & 461 & 1850 & 1130 & 3200 \\
33 & 53 & 2211 & 537 & 2100 & 1300 & 3450 \\
34 & 72 & 2262 & 476 & 2273 & 1260 & 3400 \\
35 & 100 & 2537 & 521 & 2465 & 1500 & 3880 \\
36 & 224 & 2759 & 489 & 2715 & 1640 & 4330 \\
37 & 538 & 2937 & 449 & 2900 & 1700 & 4725 \\
38 & 1109 & 3115 & 431 & 3100 & 1700 & 4860 \\
39 & 1663 & 3202 & 401 & 3200 & 2000 & 4680 \\
40 & 1531 & 3318 & 427 & 3300 & 1900 & 4900 \\
41 & 693 & 3396 & 449 & 3400 & 1890 & 4630 \\
42 & 167 & 3374 & 472 & 3350 & 2110 & 4830 \\
\hline
\end{tabular}

SD: standard deviation.

TABLE 3: Estimated birth weight percentiles for gestational age for male Cameroonian infants.

\begin{tabular}{|c|c|c|c|c|c|c|c|c|c|}
\hline \multirow{2}{*}{$\begin{array}{l}\text { Gestational } \\
\text { age (weeks) }\end{array}$} & \multicolumn{9}{|c|}{ Estimated male percentile birth weights (grams) } \\
\hline & $\mathrm{C} 3$ & $\mathrm{C} 5$ & $\mathrm{C} 10$ & $\mathrm{C} 25$ & $\mathrm{C} 50$ & C75 & $\mathrm{C} 90$ & C95 & C97 \\
\hline 28 & 906 & 940 & 1008 & 1112 & 227 & 1348 & 170 & 1549 & \\
\hline 29 & 1002 & 1048 & 1120 & 1240 & 1372 & 1512 & 1652 & 743 & 1804 \\
\hline 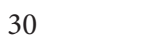 & 1099 & 1152 & 1234 & 1371 & 1522 & 1682 & 1841 & 945 & 2015 \\
\hline & 02 & 3 & 57 & 14 & & 71 & 554 & 172 & 52 \\
\hline & 23 & 3 & 2 & & & 8 & 0 & & \\
\hline & 74 & & 1 & 1892 & & 59 & 2613 & 2770 & 2876 \\
\hline & 553 & 1743 & 1884 & 2120 & 2379 & 2651 & 2921 & 3094 & 3212 \\
\hline & 855 & 1952 & 2103 & 2354 & 2630 & 2917 & 3202 & 3384 & 3507 \\
\hline & 63 & 2162 & 2316 & 2570 & 2848 & 3136 & 3420 & 3601 & 372 \\
\hline & 58 & 2356 & 2507 & 2757 & 3029 & 3310 & 3585 & 3760 & 387 \\
\hline 38 & 25 & 2523 & 2674 & 2922 & 3192 & 3469 & 3740 & 3912 & 4027 \\
\hline 39 & 2548 & 2649 & 2803 & 3057 & 3332 & 3614 & 3889 & 4063 & 4180 \\
\hline . & 2627 & 2732 & 2892 & 3156 & 3441 & 3734 & 4018 & 4198 & 4318 \\
\hline 2 & 2686 & 2794 & 2961 & 3235 & 3531 & 3834 & 4128 & 4313 & 4437 \\
\hline 42 & 2730 & 2843 & 3015 & 3298 & 3603 & 3916 & 4218 & 4409 & 4536 \\
\hline
\end{tabular}

the time of embryo implantation [13]. The gestational age in our study was estimated from the last menstrual period unlike in the French study where it was calculated from ultrasound dating. One immediate impact of using specific birth weight charts for different ethnic or racial groups is that it permits the identification of the true proportion of macrosomic babies (birth weight above 90th percentile) and small for date babies (birth weight under 10th percentile) born from mothers with complications such as gestational diabetes, preeclampsia, malaria, and anemia. 
TABLE 4: Estimated birth weight percentiles for gestational age for female Cameroonian infants.

\begin{tabular}{lccccccccc}
\hline Gestational & \multicolumn{1}{c}{ Estimated female percentile birth weights (grams) } \\
age (weeks) & C3 & C5 & C10 & C25 & C50 & C75 & C90 & C95 & C97 \\
\hline 28 & 902 & 936 & 991 & 1087 & 1201 & 1336 & 1500 & 1625 & 1719 \\
29 & 1004 & 1048 & 1119 & 1246 & 1397 & 1579 & 1801 & 1970 & 2099 \\
30 & 1098 & 1153 & 1243 & 1405 & 1601 & 1839 & 2129 & 2350 & 2517 \\
31 & 1191 & 1258 & 1369 & 1569 & 1812 & 2107 & 2462 & 2730 & 2932 \\
32 & 1301 & 1380 & 1509 & 1741 & 2021 & 2355 & 2749 & 3039 & 3253 \\
33 & 1448 & 1536 & 1678 & 1930 & 2229 & 2576 & 2971 & 3253 & 3457 \\
34 & 1639 & 1732 & 1880 & 2138 & 2436 & 2771 & 3138 & 3392 & 3572 \\
35 & 1858 & 1952 & 2101 & 2356 & 2643 & 2957 & 3289 & 3513 & 3669 \\
36 & 2076 & 2171 & 2318 & 2566 & 2841 & 3136 & 3438 & 3638 & 3775 \\
37 & 2272 & 2367 & 2513 & 2757 & 3023 & 3303 & 3585 & 3768 & 3893 \\
38 & 2435 & 2531 & 2679 & 2924 & 3190 & 3465 & 3738 & 3913 & 4031 \\
39 & 2552 & 2653 & 2807 & 3060 & 3333 & 3613 & 3888 & 4062 & 4178 \\
40 & 2619 & 2726 & 2890 & 3157 & 3444 & 3735 & 4017 & 4194 & 4313 \\
41 & 2632 & 2749 & 2926 & 3215 & 3522 & 3833 & 4129 & 4313 & 4436 \\
42 & 2576 & 2706 & 2904 & 3225 & 3564 & 3904 & 4224 & 4421 & 4551 \\
\hline
\end{tabular}

However, this study has some limits. Our data was collected from two hospitals in the urban area; thus the rural population was not well represented. Gestational age may be inaccurate when estimated from the last menstrual period. Parity was not taken into consideration when constructing our reference curves. To minimize these errors, we attempted to correct the data by identifying and excluding the outliers.

\section{Conclusion}

Our study established the birth weight percentile charts for gestational age and sex based on the Cameroonian singleton births. These charts represent the Cameroonian population better than the European or American charts. The differences in curves of birth weights for gestational age observed between the Cameroonian, Botswanan, American, and French populations confirm the geographical variation of birth weights and suggest the importance of establishing the regional birth weight norms. However, there is need to carry out a large multicentric study which will be more representative of the urban and rural populations in our country.

\section{Conflict of Interests}

The authors declare that there is no conflict of interests regarding the publication of this paper.

\section{References}

[1] S. Bonellie, J. Chalmers, R. Gray, I. Greer, S. Jarvis, and C. Williams, "Centile charts for birthweight for gestational age for Scottish singleton births," BMC Pregnancy \& Childbirth, vol. 8, article 5, 2008.
[2] A. J. Wilcox and R. Skjoerven, "Birth weight and perinatal mortality: the effect of gestational age," American Journal of Public Health, vol. 82, no. 3, pp. 378-382, 1992.

[3] United Nations Children's Fund and World Health Organization, Low Birthweight: Country, Regional and Global Estimates, UNICEF, New York, NY, USA, 2004.

[4] A. K. Blanc and T. Wardlaw, "Monitoring low birth weight: an evaluation of international estimates and an updated estimation procedure," Bulletin of the World Health Organization, vol. 83, no. 3, pp. 178-185, 2005.

[5] R. J. David and J. W. Collins Jr., "Differing birth weight among infants of US-born Blacks, African-born Blacks, and US-born Whites," The New England Journal of Medicine, vol. 337, no. 17, pp. 1209-1214, 1997.

[6] J. P. R. Doornbos, H. J. Nordbeck, A. E. Van Enk, A. S. Muller, and P. E. Treffers, "Differential birthweights and the clinical relevance of birthweight standards in a multiethnic society," International Journal of Gynecology \& Obstetrics, vol. 34, no. 4, pp. 319-324, 1991.

[7] L. T. Matthews, H. J. Ribaudo, N. K. Parekh et al., "Birth weight for gestational age norms for a large cohort of infants born to HIV-negative women in Botswana compared with norms for US-born black infants," BMC Pediatrics, vol. 11, article 115, 2011.

[8] B. Leroy and F. Lefort, "The weight and size of newborn infants at birth," Revue Francaise de Gynecologie et d'Obstetrique, vol. 66, no. 6, pp. 391-396, 1971.

[9] N. Mamelle, F. Munoz, and H. Grandjean, "Foetal growth from AUDIPOG study-I. Establishment of reference curves," Journal de Gynecologie Obstetrique et Biologie de la Reproduction, vol. 25, no. 1, pp. 61-70, 1996.

[10] P. J. Foster and T. Kecojevié, "Reference growth charts for Saudi Arabian children and adolescents," Research Report no. 12, Probability and Statistics Group, School of Mathematics, the University of Manchester, 2009.

[11] S. van Buuren and M. Fredriks, "Worm plot: a simple diagnostic device for modelling growth reference curves," Statistics in Medicine, vol. 20, no. 8, pp. 1259-1277, 2001.

[12] M. S. Kramer, R. W. Platt, S. W. Wen et al., "A new and improved population-based Canadian reference for birth weight for gestational age," Pediatrics, vol. 108, no. 2, article e35, 2001.

[13] A. P. E. Pereira, M. A. B. Dias, M. H. Bastos, S. G. N. da Gama, and M.-D. C. Leal, "Determining gestational age for public health care users in Brazil: comparison of methods and algorithm creation," BMC Research Notes, vol. 6, article 60, 2013. 


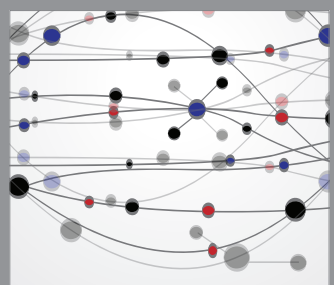

The Scientific World Journal
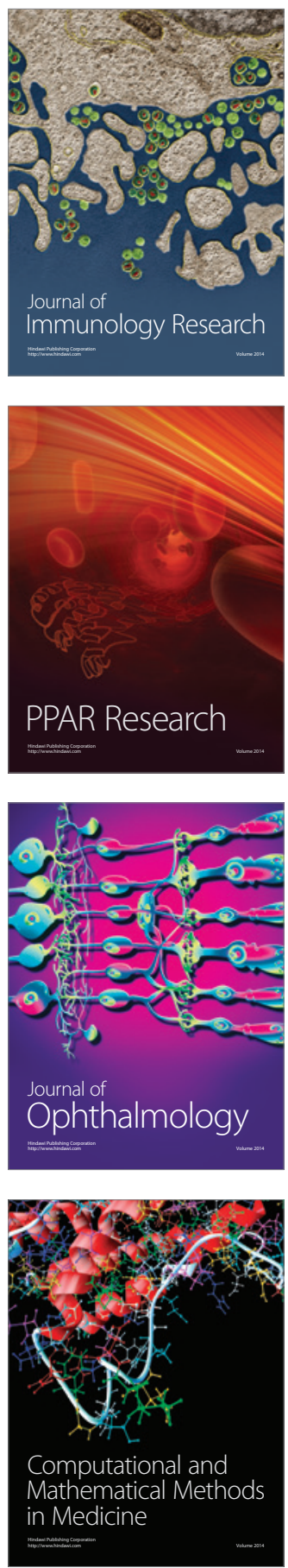

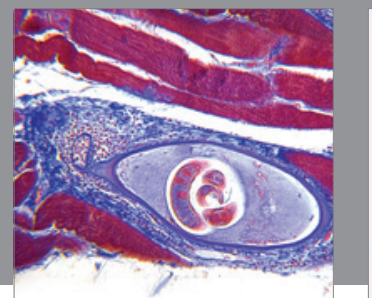

Gastroenterology

Research and Practice
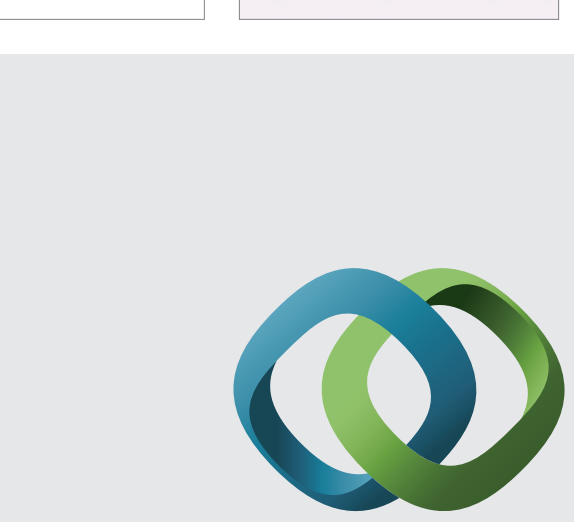

\section{Hindawi}

Submit your manuscripts at

http://www.hindawi.com
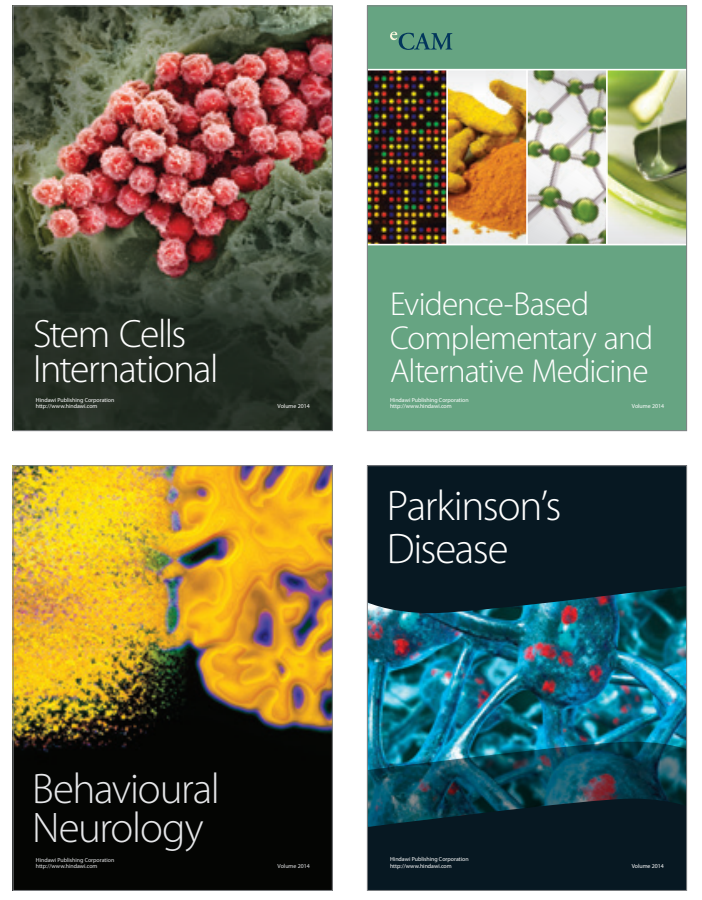
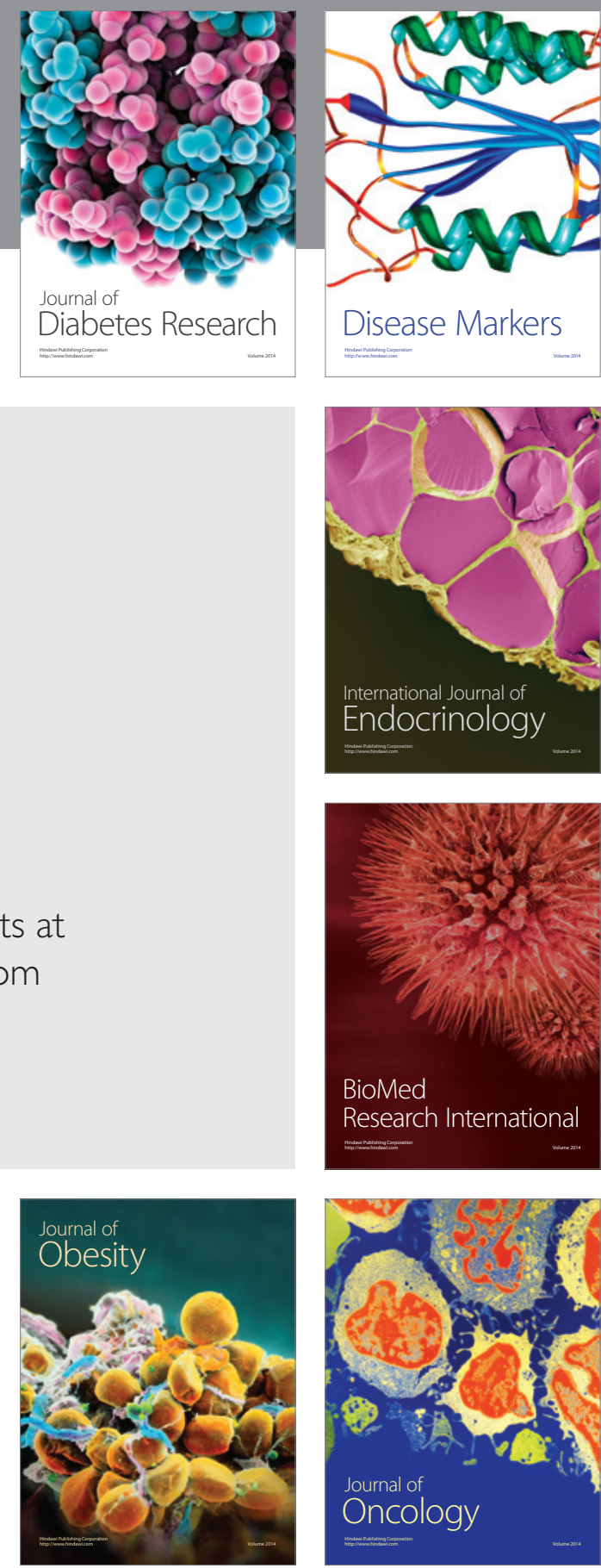

Disease Markers
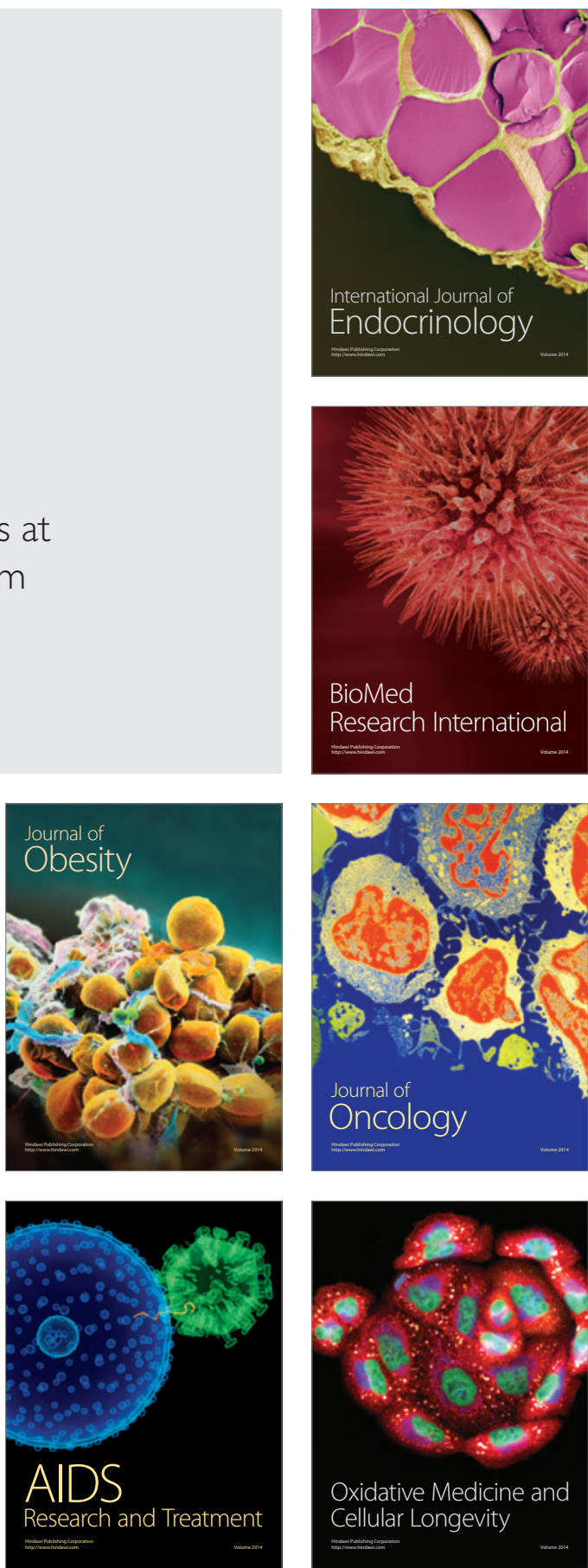